\title{
Loss of the Creature: The Obscuring of Inclusivity in Classroom Discourse
}

\author{
Lesley A. Rex
}

\begin{abstract}
Amidst few empirical studies of the effects of high stakes testing on classroom talk, this study concretely illustrates erosion of inclusive teacher-student interaction. Using discourse analysis, it compares $K-12$ classroom instructional practices before and after the imposition of standardized testing and illuminates the negative transformation of five inclusionary discursive practices. Before testing mandates: 1) diversity was regarded as a resource for opportunities to learn something valuable; 2) standards for academic achievement provided a wide range of possible performances; 3) teachers and students were flexible in their stances toward what constituted academic performance; 4) students" constructed student "selves" were part of a dialogue about academic expectations; and 5) students' personal texts were a legitimate part of the curriculum. In test-impacted classrooms, in contrast, meanings for diversity, performance standards, and performance stances contracted, and talk about students' selves and their personal texts narrowed. In an illustrative case, an "at risk" student's effort to express his point is overridden by his teacher's well-meaning urgency to clean up his prose to meet testing expectations for literate language. The discourse analytic approach informing this research can also inform teacher education and professional development. Keywords: high-stakes testing, classroom discourse, teacher-student interaction, literacy education
\end{abstract}

Having a student with Tourette's Syndrome transformed Christopher Wessman's teaching and his students' learning. An assistant professor of English at New Jersey City University, Dr. Wessman described how the student's outbursts, though disruptive and difficult to ignore at first, unleashed a raw creativity and spontaneity in his class as the semester progressed. His students' writing improved, he said, because they "had been 'loosened up' by the forbidden, the taboo smashing that had taken place over the months." The interruptions that might have led to a disastrous classroom experience, he concluded, as a result of the "Tourette's-inspired chemistry" of the class, brought him to "value the raw, the uncensored, the subterranean self above almost all other things in the writing classroom" (Wessman, 2000, p. 30).

Stories like this remind us of the importance of classroom teachers' flexibility in their moment-to-moment interactions with students. They also point out the centrality of discourse- of the ways students and teachers talk with each other-in the difficult process of building a productively inclusive learning environment. Professor Wasserman and his class viewed his student's condition not as a disability, but as an opportunity to develop one's writing and oneself as a communicator. It is unlikely that Professor Wasserman had to deal with high stakes exit testing pressures. In

Lesley A. Rex (PhD, University of Michigan), 2022 School of Education, University of Michigan, $619 \mathrm{E}$ University, Ann Arbor, MI 48109-1259. Phone: 734-647-1988. E-mail: rex@umich.edu. I wish to thank the Spencer Foundation whose funding made aspects of the studies reported here possible, though the opinions expressed are solely my responsibility. I want especially to thank the teachers whose dedication to improving their practice and the inequities of schooling led them to open their classrooms for my studies. Their commitment to career-long professional learning makes my work possible and worthwhile. 
today's K-12 standardized test assessment environment, teachers of English language arts who are doing the difficult work of fostering an inclusively participatory learning environment also have to manage the demands of test preparation.

In this article, I am concerned about illuminating changes in the discursive practices of teachers who are pressured by accountability measures. Competing demands that teachers improve students' learning while at the same time raising their standardized test scores have pushed even the most well meaning professionals into instructional dilemmas of which they are often unaware. In previous studies (e.g., Rex, 2001b; Rex \& Nelson, in press), I observed committed teachers, who defended and cultivated inclusion objectives, unintentionally stymie those same objectives with pre-emptive test preparation. Their cases provide the inspiration for this article, which compares classroom discursive practices that enable inclusive engagement with discursive practices that make inclusive engagement more difficult. These practices are taken from the findings of a cross case analysis of eight studies with common research methods. These are microethnographic studies of teaching and learning practices I conducted in five classrooms-three before and two after test preparation-dominated instruction. My purpose in this comparison is to address rhetoric about the positive and negative effects of testing. In particular, I aim to assist educators and teacher educators in understanding some of testings' less observed, fundamentally important influences. Finally, I offer concrete suggestions for how the research methodology that illuminated confounding influences can also be a means for teachers to deal with them.

\section{Research into the Impact of High Stakes Testing on Classroom Instruction}

We have little research into the effect of test-based reform on day-to-day classroom instructional practices and its influence on curriculum, though we have a sizable literature dealing with its institutional impact. In a review of high stakes testing as educational reform over the past 50 years, Linn (2000) examined its impact on the institution of schooling and concluded that "unintended negative effects of highstakes accountability often outweigh intended positive effects" (p. 14). These effects are visible in, for example, student enrollment and teacher satisfaction and retention rates. As an illustration, recent studies of current programs have reported that in places like Texas, even as test scores have gone up substantially, drop out rates of minority students have increased (Pipho, 2000).

These findings and related qualitative research indicate that standardized testing has contributed to already high anxiety and confusion in $\mathrm{K}-12$ education (Corbett \& Wilson, 1991). Testing as a method of reform is being challenged for de-skilling and de-professionalizing teaching (Darling-Hammond, 1988; McNeil, 1988, 2000). Amidst serious allegations of dire negative effects, including the disproportionate high failure rates among "at risk" students such as students with disabilities and immigrant students, is the troubling claim that accountability pressures have led to a reshaping of content area curriculums and instructional methods. Studies report that teachers say all they do is prepare students for the test (Graue, 1993; Lieberman, 1992; Shepard, 2000). "What has happened is that standardized tests have been elevated to where they are the curriculum," claimed Ann Lieberman, a senior scholar at the Carnegie Foundation for the Advancement of Teaching. "What we are doing is narrowing the kinds of activities and learning opportunities for students rather than 
broadening and deepening them" (quoted in Olson, 2000, p. 2 ). Nevertheless, studies illuminating what occurs as curriculum is enacted through teachers' instructional practices are few.

In his study of New York teachers' perceptions of changes in their state's testing program, S.G. Grant (2001) reviewed the literature on the relationship between high stakes test scores, professional development and classroom instruction. Grant found that few empirical studies represent the relationship between instruction and the tests they administer. Those that do, present a mixed picture of claims that does little to inform our understanding of how testing accountability pressure influences what teachers do in their classroom instruction. All these studies allow us to say is that testing does seem to influence teachers, and that the influence transfers to a greater or lesser extent to classroom practices.

In my recent scholarship, I have attempted to add clarity and specificity to this research literature by describing influences on classroom instruction of top down pressures on teachers to prepare their students for testing. I have studied changes over time in the instructional conversations between teachers and students that contribute to less inclusive practices.

\section{Inclusive Participation through Classroom Dialogue}

When I use the phrase "inclusive practices," I am applying the more general concept of inclusion originated by scholars who study the integration of students with disabilities into general classrooms (see discussion of this issue in Palincsar, 1997) to include the integration of students classified as "at risk" of failure or dropping out. The term "inclusive education" is being applied more broadly by scholars in the United Kingdom and the United States to mean successful participation by all students in the generation of greater educational options (see for example Ainscow, 1993; Skrtic, 1991; Skrtic, Sailor, \& Gee, 1991; Slee, 1993). These and other scholars interested in the problems of integrating students currently unfairly sorted and tracked as different in "ability" or "readiness" call for research that will reconceptualize why and how successful classroom integration can be achieved (see Bos \& Fletcher, 1997; Forman \& McCormick, 1995; Keogh, Gallimore, \& Weisner, 1997).

To study the why and how of inclusionary participation, I apply a sociocultural lens to observe classroom discourse interactions. This lens is based on a constellation of assumptions about how teachers teach and how students learn. The first is that a classroom learning environment becomes a culture with common patterns of perceiving, believing, acting and evaluating (Goodenough, 1981). The second is that language or discourse is a dominant medium through which the meaning of those patterns is built and evolves over time (Geertz, 1973). The third assumption holds that these common patterns are constructed and held in place by social practices (Bourdieu, 1977, 1990; Rex, 2002). From this perspective, as the manager of discourses that orient students to what is expected, the teacher is the primary sociocultural mediator of inclusive participation and learning (Rex, 2001a). By managing who gets to speak about what and evaluating the quality of the performance, the teacher mediates the process of integrating (or not integrating) "at risk" students' background experiences and cultural knowledge into classroom curriculum and instructional activity (Keogh et al., 1997).

In my work, I have derived the concept of "interactional inclusion" to elaborate the role of discourse in inclusive classrooms (Rex, 2000). This concept builds upon educational scholarship about member-constructed classroom cultures as communi- 
cative and referential systems (e.g., Cazden, 2001; Heath, 1983; Santa Barbara Classroom Discourse Group, 1992). It also draws from interactional sociolinguistic (e.g., Gumperz, 1986) approaches to studying spoken classroom discourse. This method illuminates relationships between particular ways of using language, occasions of its use, and social rules that create the conditions for learning. Studying what individual classroom members say or do, with whom, when and how they say or do it, under what conditions, for what individual and group purposes, and with what outcomes illuminates the learning culture of that classroom from each member's point of view. Such studies reveal how individual members discursively participate in the social and academic knowledge and procedures they need to become members of the group (Green \& Dixon, 1993). They show the principles or rules for how individuals can proceed as members to participate in the "take up" (Edwards \& Mercer, 1987) of academic learning opportunities (Alton-Lee and Nuthall, 1992; Meyers, 1993; Tuyay, Jennings, \& Dixon, 1995) to become academically literate (Cochran-Smith, 1984).

In the ways teachers speak and write to their students they orient their students to how they can participate in the construction of collective academic knowledge (e.g., reading, writing, and speaking practices, procedures, and subject matter) and social knowledge (e.g., social roles and relationships and attendant rules for social participation). In turn, students are shaped by and shape the learning culture and knowledge of the classroom as they interact with it. In their readings, writings, and speakings, they present themselves as particular kinds of students with particular kinds of knowledge to fit the social and knowledge-building process underway (Fairclough, 1993). That is, students position themselves or step into particular social and academic roles as readers, writers, and speakers in response to how they are positioned by their teacher's and classmates' responses, what Gee (1996) refers to as "socioliteracy."

Discursive interactions are central because classroom language (including the classroom's principles for proceeding and performing with language) is a resource needed by all classroom members to sustain participatory membership and learning (e.g., Borko \& Eisenhart, 1989; Collins, 1986; Gee \& Green, 1998; Gilmore, 1987; Moll, Diaz, Estrada, \& Lopes, 1992). Students who are struggling must learn the discourse to become participatory members, to learn the required academic knowledge, and to display that learning according to acceptable performance expectations. Concurrently, the dominant social and academic patterns must accommodate the struggling students' discourses (Rex, 2001a).

\section{Using Multiple Methods to Explore Classroom Discourse}

In my research of inclusively participatory classrooms, I describe how teachers and students build knowledge over time and the consequences of particular discursive practices for student participation and performance. I describe the patterns formed from moments of classroom talk as teachers and students negotiate and construct what counts as appropriate performances. By applying the same research approach and similar logic of inquiry, I explore various kinds of social and academic inclusion, which I assess as having been accomplished through observation of classroom performance, test scores, grades, attendance records, student surveys, and interviews with class members. By combining an ethnographic approach with various methods of discourse analysis (i.e., conversation analysis, interactional sociolinguistic analysis, interactional ethnographic analysis, and critical discourse analysis) I observe 
extensive strings of talk over stretches of activity and how they play out in performances of reading or writing. While studying the five classrooms I refer to in this article, I was a daily observer/participant for a semester or more while an ethnographer in each of the schools for at least two years. While collecting field notes, video recordings, and document data, I evolved increasingly focused research questions, made comparative analyses from multiple data sources, and triangulated interpretations, which led to selecting key data points to serve as telling cases (Mitchell, 1984). This long term, ethnographic approach to selecting research sites, questions, and key data makes it possible to illustrate through micro analyses discursive practices that constitute or constrain inclusive participation within unique sites. Keeping the research approach, methods, and logic of inquiry constant across the study sites, enhances validity of cross case comparisons (Donmoyer, 1990). For full details of research contexts, data collection and analysis methods, and results, please refer to Rex, 1994, 1997, 2000, 2001a, 2001b; Rex \& McEachen, 1999; Rex, Murnen, Hobbs, \& McEachen, 2002; Rex \& Nelson, 2001, in press.

\section{Describing Inclusive Classrooms Prior to the Imposition of Standardized Testing}

In this section I summarize the studies I conducted in three inclusive classrooms and the results of my secondary analysis of comparable discursive data related to inclusive practices common to all three.

In a study of a twelfth grade Advanced Placement English class, I described the integration of four academically high performing students who took unique stances toward what and how they were learning (Rex, 1994). For example, one of the students who learned to expertly perform the academic genre of persuasive expository essay writing believed such writing and related ways of reading were "killing her poetic soul." I described how she and the other students assumed complex roles and relationships with their teacher that allowed them to maintain their stances while engaging successfully in the work of the class.

A series of three studies described how the discourse practices promoted by an English teacher made it possible for students designated as "general" to learn how to perform successfully as readers and writers with their "gifted and talented" classmates. I demonstrated how the teacher promoted discourses that "oriented" students so they could understand how to become literate members of the classroom. Analyses illustrated how these discourses served to maintain an opportune learning culture as well as transform expectations for performance to include all students' participation (Rex, 1997, 2001a; Rex \& McEachen, 1999).

Another research study described the inclusionary practices in a classroom that was part of a state-funded school restructuring plan to detrack and integrate all entering freshman. The course integrated previously tracked "gifted and talented," "general," "ESL," and students with "learning disabilities" to build social community, appreciation for diversity, a culture of success, and practices supportive of academic competence. The teacher in this classroom was adept at bringing all the students into classroom conversations that built interest in what others had to say and in what they might learn. Over its first five years, most members and stakeholders believed the course achieved its goal of successful social and academic integration (Rex, 2000).

Coding the instructional discourse practices across these three classrooms for common conditions relevant to inclusivity produced five patterns: 
1. Diversity was regarded as a resource for opportunities to learn something valuable.

2. Standards for academic achievement provided a wide range of possible performances.

3. Teachers and students were flexible in their stances toward what constituted academic performance.

4. Students' constructed student "selves" were part of a dialogue about academic expectations.

5. Students' personal texts were a legitimate part of the curriculum.

\section{Describing Formerly Inclusive Classrooms After the Imposition of Standardized Testing}

Next, I turn to the results from a secondary analysis of data from two recent studies of classrooms intended to be inclusively participatory. I comparatively investigated the practices of two high school English teachers as they responded to mandated high stakes test accountability. (For detailed presentations of contexts, methods, and results, refer to Rex, 2001b and Rex \& Nelson, 2001, in press.) Both teachers had a powerful commitment to their students, and both attempted to forward their students' success by building inclusive conditions in their classrooms. Most of their students had been low achievers in English since they began school. Over the previous five years, the district had provided professional development, specialist support, and school site leadership, along with accountability measures, to assist teachers in managing increased expectations for standards and high stakes test performance. The two teachers were supportive of these efforts and believed they could maintain inclusive practices while teaching to the test so that their low achieving students could perform well.

Their classroom practices indicated that despite the best of intentions and district support, both teachers unwittingly stymied their own objectives (Rex \& Nelson, 2001, in press). While many students made gains in performance within their classrooms, low achievers' test scores did not significantly improve, nor did students sustain inclusive learning engagement in the class. Several factors emerged from analyzing the instructional discourses in the two classrooms. When students were practicing for the reading and writing portions of the tests, the interactions they engaged in with their teachers constructed views of what being a reader, writer, and learner meant that competed with their regular class curriculum. All the work to be "real writers" and "real thinkers" promoted by their teachers was eclipsed by a competing expectation to think differently about what constituted effective reading and writing in preparation for testing (Rex \& Nelson, 2001, in press).

The first study also pointed out that even when a school's policy toward curriculum and testing is aligned, teachers take different stances in relation to the policy. Consequently, in the second study, I described how students received differentsometimes conflicting-messages about how to write from one English classroom to the next (Rex, 2001b). I observed that students were taught differently about: where authority resides for the rules of writing, their own authority as writers, how writers use language, the role of teachers in giving writing instruction, and the source of blame for inadequate performance.

In coding across the discourse practices in these two classrooms in relation to the pattern categories that emerged in the inclusively participatory classrooms, we noted 
a narrowing of the meanings for diversity, performance standards, and performance stances and elimination of students' selves and their personal texts:

1. Diversity is redefined as opportunities to learn the discourse of the test.

2. Standards for academic achievement provide a much narrower range of possible performances.

3. Teachers and students take specific stances toward what constitutes academic performance.

4. Students' constructed student "selves" are eliminated from dialogue about academic expectations.

5. Students' personal texts are excluded from the curriculum.

\section{Analyzing the Discourse of a Classroom Newly Facing Standardized Testing: An Illustrative Case}

In order to illustrate in concrete terms the kind of discourse patterns taking hold in classrooms newly dominated by test preparation mandates, I present the following analysis of classroom episodes, which are more fully contextualized in Rex \& Nelson (2001, in press). The interchange between teacher, Marita, and student, Nathan, illustrates an instructional discourse practice that contributed to the five inclusionarycompromising conditions. In providing the example, I do not mean to suggest that this incident alone undermines inclusive learning. The interaction is presented to illuminate how instructional moments contribute to often unrealized and unintended conditions when they accumulate over time.

Marita had been leading her class through a paragraph writing exercise in preparation for their high stakes test. She had prompted their writing by asking them if drugs affected them, their families, and communities the way they affected the main character of the novel they were reading. Using a graphic organizer template, students were to write sentences in boxes that represented sentences in the paragraph. The following interaction occurred as Marita was walking around the class reading the students' first box topic sentences. In this segment of talk, Marita and Nathan, a student from the inner city with poor performance scores in English, are discussing his topic sentence. (See Talk Sample 1).

Marita and Nathan clearly have different views of what to accomplish in improving the quality of his workmanship. Nathan begins by paraphrasing what he means by the sentence he has written (Turn 1), and Marita responds to what he has said by challenging its veracity with, "That wouldn't be true though" (Turn 2). Nathan argues back by giving evidence that warrants his argument (Turn 3). Unlike Alice, his whole community stays together and is drug free because they are athletes. This type of interchange is common in this particular classroom (Rex \& Nelson, in press). It is the established way of talking about readings and writings. Marita encourages students to think about the actions of the characters and themes in the books they read by comparing them to their experiences and challenging their thinking about what is best, right, and healthy in life. This test prep exercise had come after a series of activities about Go Ask Alice, a 1970's novel about a teenage girl's descent into drug addiction. In an animated debate in response to Marita's question, "What influenced Alice to avoid her problems?" students called on references to the text to blame either Alice's mother or father. Through such discussions, directed journal prompts (such as "What do you wish your parents knew?"), and an essay, Marita had directed students to compare the character's issues to their own. 
TALK SAMPLE 1

Instance of Teacher Redirecting Talk from Student Self Expression to Test-Oriented Correction

\begin{tabular}{|c|c|c|}
\hline 1 & Nathan & Ok what I'm saying drugs doesn't affect me and my family and my community. \\
\hline 2 & Marita & That wouldn't be true though $=$ \\
\hline 3 & Nathan & $\begin{array}{l}=\text { It } i \text { s true. Where I live we say no to drugs. The whole community we all stay } \\
\text { together and we are drug free 'cause we all 'r athletes. }\end{array}$ \\
\hline 4 & Marita & $\begin{array}{l}\text { (She silently reads Nathan's sentence }(.5) \text { before rephrasing it.) The way drugs } \\
\text { affects Alice (.5) does not affect my family, friends, or community. That's } \\
\text { how it should [sound. }\end{array}$ \\
\hline 5 & Nathan & [why I'm going to explain why. I'm gonna explain \\
\hline 6 & Marita & $\begin{array}{l}\text { OOkay. Did you hear what I just said? What did I just say? The way drugs affect } \\
\text { Alice = }\end{array}$ \\
\hline 7 & Nathan & $=$ does not \\
\hline 8 & Marita & $\begin{array}{l}\text { Wait. Listen. (She reads his sentence) The way drugs affect Alice they don't } \\
\text { affect my family friends and community. Is that how you talk? }\end{array}$ \\
\hline 9 & Nathan & I'm gonna say does not. \\
\hline 10 & Marita & [Is that how you talk? \\
\hline 11 & Nathan & I'm gonna say does not. \\
\hline 12 & Marita & Answer the question. Is that how you talk? \\
\hline 13 & Nathan & Uhuh \\
\hline 14 & Marita & Okay. Then you need to reread before you \\
\hline 15 & Nathan & uhuh. Okay \\
\hline 16 & Marita & Read it. Okay. Write it like it should be. \\
\hline 17 & Nathan & uhuh. Okay. \\
\hline
\end{tabular}

Transcription key:

. indicates sentence final falling intonation.

, indicates clause-final intonation ("more to come").

... three dots in transcripts indicate pause of $1 / 2$ second or more.

[ brackets show overlap of two voices at once.

$=$ equals sign indicates latching of speakers with no perceptible inter-turn pause.

- dash occurs when the speaker interrupts him or herself.

CAPS indicate emphatic stress.

(.5) pause length in tenths of seconds.

xxxx indicates unintelligible speech.

What happens next demonstrates the shifts of focus that occur whenever Marita taught to the test. Marita turned her attention away from the students' ideas and to correcting the form of their expression (Turn 4). She corrected the grammatical and syntactical form of Nathan's sentence. At first, Nathan did not make the shift with her. He continued to argue for the truth of his topic sentence (Turn 5), while Marita pushed him to listen to how she was reading his sentence (Turn 6). She succeeded in stopping his argument and in getting him to focus on grammatical construction. $\mathrm{He}$ reformulated the contracted "doesn't" to "does not" (Turn 9). But that was not sufficient. The point Marita wanted Nathan to understand was that he should not be writing as he talks, but rather he should "Write it like it should be" (Turn 16). Marita was telling him to focus on the form of his text and to correct it.

The relationship Nathan experienced with his writing was quite different in this interchange than it had been previously. In the regular curriculum, Nathan wrote to express himself in a way that would communicate well with an intended audience. His words were an extension of his thinking and his experience. His prose was meant to create an effect for a reader. When he corrected his prose, he improved its effectiveness. He was a craftful writer. For example, in writing about the "real world" applications of the lyrics to Stevie Wonder's song "Pastime Paradise," Marita had congratulated Nathan for drawing from his own life and from television and movies 
to "tell it like it is." In the present interchange, Nathan and his writing were being treated differently. He is not a writer, but a student who is getting it wrong. His writing should be the way it is supposed to be for the test.

On one level, we could say that Marita was doing what any good English teacher should be doing-correcting a student's incorrect grammar and telling him to be self-correcting. These are central skills for good performance in the world as well as on the test. However, I selected this moment because it so powerfully demonstrates how Marita's best intentions to teach what students must know and do unwittingly stymied her goal of keeping "at risk" students like Nathan engaged in the learning of the class. It did so because it was one of many similar moments throughout the term, moments that in isolation seem innocuous, but when they accrue can undermine inclusive participation.

Having already built the expectation that in this class Nathan's personal life is central to what he thinks about as he reads and writes, this shift to a much narrower range for defining performance more tightly inscribes who he can be as a writer. Marita speaks as though there is no flexibility in what constitutes correct performance. She does not permit Nathan's point about the difference between Alice's and his community's involvement with drugs to be a part of the discussion about the syntactical structure with which he expresses his proposition. Her response positions his personal story as material for practicing paragraph writing, and thus diminishes its importance. Since Nathan takes great pride in his abstinence from drugs, Marita's reaction can be read as dismissive. Also, the interchange is a missed opportunity for other students in the class, many of whom have been suspended for drug-related infractions, to value Nathan's knowledge and to reinforce his role as a valued class member. As her interchange with Nathan demonstrates, Marita's concern for her students' learning the discourse of the test eclipsed her interest in her students' diverse discourses. This move prevented their stories and the selves that inhabited them to become part of the learning in ways that built and sustained inclusion.

\section{Loss of the Creature}

Nathan and Marita's interchange, when viewed in relation to the usual talk in this class, shows us how test preparation lessons can conflict with the instructional practices that effective teachers have long employed, and the results they implicate. Marita thought she was integrating test preparation into her regular practices. She had no idea that she may have been subverting them. That this clash exists and redefines classroom learning, even when teachers aim to be inclusionary, is troubling. It suggests that equitable integration is compromised by shifting practices that redefine diversity, performance standards, and personal expectations. But that still does not tell us enough. To be informative, such news should include what is lost to students and teachers. We need to understand what it is that is derailed, transformed, or missing if we are to keep the goal of inclusive practice in view.

In a classic, prescient essay about perception and commodification, writer Walker Percy (1997) noted how tourists who have been saturated with commercial photos of the Grand Canyon before their actual visit value "seeing" the canyon through Technicolor compositions. Sadly, their ways of interacting with the trails and the vistas are established by Kodak standards reified in snapshots of Kodak moments. Percy tells us that when visitors arrive "instead of looking at it, [they] photograph it. There is no confrontation at all" (p. 47). They stand at the edge of the complex marvel and look for the panoramas they remember from the postcards and travel 
brochures, so they can photograph their spouses and children inside these frames. He called this "the loss of the creature."

Percy's concept is a resonant metaphor for how teachers and teacher educators might think of what is lost when well-meaning teachers see through the representations of reading, writing, and speaking imposed by standards accountability and high stakes test preparation. Teachers ask students to step into these images, which detach teachers from "seeing" knowledge and their students in ways that connect their students with the curriculum they are trying to teach.

\section{What Creature is Lost?}

Percy's metaphor offers a useful heuristic for looking at another segment of classroom talk, this time in one of the pre-accountability pressure classrooms (Rex, 2000). Analysis of instructional talk before the teacher felt pressured by test preparation should yield a view of "the creature" that disappears. In this ninth-grade class, the school had intentionally combined previously tracked "gifted and talented," "general," "ESL," and students with "learning disabilities" in an attempt to diffuse the negative influences of tracking. The curriculum combined English, science, social studies, and math activities and teachers to successfully introduce students to each other and to high school academics. I have selected an excerpt of talk that has direct bearing on the push for developmental curriculum standards benchmarks teachers are held accountable for in states like California where this classroom is located (http://www.cde.ca.gov/standards/reading/). Arguing a point from evidence or making a case is central to reading and writing instruction as observed in curriculum, in standards documents, and in student work from early elementary school onward. It is a structure that dominates the reading and writing portions of state achievement tests.

As I analyzed the transcript, I was guided by questions high school English teachers regularly face when teaching the discourse of standards and testing. What if their students are struggling with the kind of student they need to be, or with the role of school in their lives? What if they don't believe they need to talk, read, or write in the ways the high stakes tests imply they should? What if their students don't have any experience with or interest in engaging in the classroom's discourses of achievement? What classroom conversations are lost and what opportunities for inclusion disappear when much of the talk is about reading and writing as they appear on the test?

Led by Jack, an experienced English teacher, the classroom discussion from which the segment is excerpted is initiated by Lisa, who was bilingual and had recently emigrated from Texas with her Spanish-speaking parents. She had the following conversation with Jack early in the term when he was collecting her homework and she had difficulty explaining what she had written (see Talk Sample 2 ). The stances she took in the conversation reappeared throughout the term in many other interactions as I will illustrate further along.

At fourteen, Lisa's life plan did not include reading (Turn 7). However, she would do her best to comply with school homework protocols so as not to invoke punitive measures. She had worked out a system to keep up appearances (Turn 1), what Bloome, Puro \& Theodorou (1989) have called "procedural display," that had little to do with her life goals. Jack saw his task as convincing Lisa to change her stance toward homework and reading and writing practices to make them a more "genuine" part of her learning (Turns 4 and 6). It was his goal for all his students. In 


\begin{tabular}{|c|c|c|}
\hline 1 & Lisa & $\begin{array}{l}\text { Well, you know, with doing homework, I don't do it; my friend does and she gives it } \\
\text { to me. }\end{array}$ \\
\hline 2 & Jack & What if you don't have any friends that are in the same class and you're on your own? \\
\hline 3 & Lisa & Well, I make some. (Laughs) \\
\hline 4 & Jack & $\begin{array}{l}\text { Well, I mean, studying with friends is ok, but if you're just copying the homework } \\
\text { you're missing out on why you're here in school. }\end{array}$ \\
\hline 5 & Lisa & Why? \\
\hline 6 & Jack & $\begin{array}{l}\text { If you're here and everybody's doing all your work for you then you get out and you } \\
\text { don't know anything after four years. Why not do it yourself? }\end{array}$ \\
\hline 7 & Lisa & $\begin{array}{l}\text { Well, anyway, something might happen and I might not go to college. And in my case } \\
\text { I'm gonna go and stay with my boyfriend at home, and that will be my life. I don't } \\
\text { need to read. }\end{array}$ \\
\hline
\end{tabular}

addition to academic texts, he asked students to draw from their own life stories to question and make and support claims with each other. To do so students were taught to ask and pursue the answers to their "genuine questions," or, as Jack explained them, questions that one "really" wanted to know the answer to. For example, a way of reading academic texts was to keep a running log of one's genuine questions about the text's contents or ideas. One way of "notemaking" to accompany students' "notetaking" was to ask genuine questions to challenge or extend the information in the notes. Solving math problems involved asking peer and teacher collaborators genuine questions about what was being requested in the problem and the significance of particular information or a particular step. Talking about current events meant asking genuine questions linking one's own experience to the circumstances in the report. At the end of the course, students wrote investigative reports, derived from their own "genuine" research question.

In Talk Sample 3(1), below, Jack made another attempt on the twenty-sixth day of class to convince Lisa, who was now doing her own homework, of the value of school work. This time, after asking a genuine question about homework habits, Jack argued during a class discussion for the need to concentrate when one does reading homework, and he was assisted by three other students-Jon, Jody, and Lydiaclassified by the school respectively as "general," "learning disabled," and "English second language" students. Together the students made a case with Jack, arguing their claims from evidence drawn, as usual, from their own experiences with school academics. For Jack, making a case was a discourse tied to transforming his student's

TALK SAMPLE 3(1)

Using Personal Experience to Make a Case for the Value of Attending to Homework

\begin{tabular}{ccl}
\hline \hline 1 & Jack & $\begin{array}{l}\text { (Most of students have their hands raised.) WHOA. See how many talk on the } \\
\text { phone and do homework at the same time. } \\
\text { (Students loudly answer) Yeah }\end{array}$ \\
2 & Jack & $\begin{array}{l}\text { Oh, no way. (Loud student talk) } \\
\text { Yeah, way. I always do that }\end{array}$ \\
4 & Lisa & You can? (Looks at Lisa) \\
5 & Jack & That's how I get my work done. \\
6 & Lisa & (Jon raises his hand) \\
7 & Jack & Yeah (T points at Jon) \\
8 & Jon had a teacher who told us that you could do more than one thing at & once ... He said that like, while you are talking you can be doing things. \\
9 & &
\end{tabular}


stances toward academic practices (Rex, 2000). Case-making was the medium through which he connected personal experience-as evidence-to claims for the benefits of school-based knowledge. It was also the medium he wanted his students to use in thinking about their personal stances and the experiences that informed them.

Lisa took the lead in the discussion by asserting students could talk on the telephone and concurrently do their homework. She told Jack she did it all the time. When he polled the class to see how many students talk on the phone while doing their homework, most of the students raised their hands and announced "yeah" (Turn 2). When he contested their claim, he was challenging their assertion that they could get their homework done effectively if they were talking to friends at the same time (Turn 3). Lisa took up the role of spokesperson for the group in asserting their claim from her own experience- "Yeah, way. I always do that" (Turn 4). When Jack questioned Lisa's assertion with "You can?" (Turn 5) he gave her permission to begin making her case, which she took up with the reassertion "that's how I get my work done" (Turn 6). At this point, Jon provided supporting evidence for Lisa's claim by telling about something a teacher once told him in a previous class: ". . . you could do more than one thing at once" (Turn 9). Lisa asserted the position of most of the students in the class, the view that homework is work to get done. She meant that homework is so onerous that having a friend to talk to as you do it makes it more bearable. Jon, in trying to provide academic authority for doing more than one thing at a time, was arguing to maintain this point of view about homework. Not only is talking to friends a relief; the practice doesn't inhibit homework productivity.

At the beginning of the interaction, Jack understood the two student views of homework as limiting. It limited their interest in taking up more effective ways of working that would increase their concentration and their academic effectiveness. In the moment, he took up the challenge to change their view and to expand their thinking about how they might do homework more productively. By making moment-to-moment choices, he managed to construct a case with the assistance of other students by using personal tellings and by making meaningful ties to other instructional knowledge that had been built during earlier reading lessons.

Next, Jack countered the point Jon was making with his evidence by asking him to consider a counter point-“... but if you are talking then other people are probably getting distracted" (Turn 10)-to which Jon agreed (Turn 11). Jody offered her personal experience in support of the teacher's point (Turn 12). Jack extended his point by referring to Stan's previous claim, which had been illustrated earlier through the use of Stan's personal experience about which music to listen to while doing homework. Jack added evidence from his own experience-"If I have music playing I can't listen to music with words, but then I start singing along with the words" (Turn 13). He restated the idea that distraction through talk or singing had a negative effect on the satisfactory completion of academic tasks.

From that point on in the interaction, Jack and Lydia built the case for his point by linking it to the difficulties of reading academic texts and by providing evidence from personal experiences (Turns 13-17). Jack initiated the tie by saying, "I don't think I can talk on the phone and do something like serious kind of reading or something. Reading, I think, requires the most concentration because especially if you are reading something difficult" (Turn 13). Lydia built on his point by asserting, "Also when you are thinking about something and you want to read something, you 
Using Personal Experience to Make a Case for the Value of Attending to Homework

\begin{tabular}{|c|c|c|}
\hline 10 & Jack & $\begin{array}{l}\text { Uhuh, what about this? The trouble is Jon, is that most people do more } \\
\text { than one thing at the same time. But if you are talking, then other } \\
\text { people are probably getting distracted. Not everybody can concentrate } \\
\text { on more than one thing at a time. (Jody raises her hand) (Jack } \\
\text { interrupts himself and points to Jody) [How do you-Yeah }\end{array}$ \\
\hline 11 & Jon & [Yeah \\
\hline 12 & Jody & $\begin{array}{l}\text { xxxxx then they start talking, and then you start talking, and then they ask } \\
\text { you something and you've been talking to yourself about your } \\
\text { homework, and then you hear your name real loud. }\end{array}$ \\
\hline 13 & Jack & $\begin{array}{l}\text { Yeah. I think maybe you could listen to-I agree with Stan. If I have music } \\
\text { playing I can't listen to music with words, but then I start singing along } \\
\text { with the words. But if I have music that's quiet in the background, that } \\
\text { doesn't distract me so much. But if it's too loud, or if it's got words, I } \\
\text { don't think I can talk on the phone and do something like serious kind } \\
\text { of reading or something. Reading, I think, requires the most } \\
\text { concentration because especially if you are reading something difficult. }\end{array}$ \\
\hline
\end{tabular}

have to, like, read it like, like, when you are looking at it you can't understand it" (Turn 14). Jack confirmed Lydia's point and built on it using personal information. "I can sometimes read something out loud, but I'll have a hard time concentrating on pronouncing the words correctly and understanding what's going on at the same time" (Turn 15). Lydia added to his experience with her own, "Like, when I'm reading something, I know what I'm reading but I'm having a hard time paying attention to it" (Turn 16). Lydia and Jack are redefining what it means to read an academic text for homework; the other class members also have the opportunity to redefine what they mean by homework reading. The interplay of the multiple tellings of personal experiences with reading and the relationships they create

TALK SAMPLE 3(3)

Using Personal Experience to Make a Case for the Value of Attending to Homework

\begin{tabular}{|c|c|c|}
\hline 14 & Lydia & $\begin{array}{l}\text { Also when you are thinking about something and you want to read something, } \\
\text { you have to, like, read it, like, like, when you are looking at it you can't } \\
\text { understand it. }\end{array}$ \\
\hline 15 & Jack & $\begin{array}{l}\text { Right. I know a lot of people that can read the words and they understand the } \\
\text { words but the meaning, the overall meaning or the main points it's not always } \\
\text { easy to take the main point even though you are reading the words. Reading out } \\
\text { loud, you know, I can sometimes read something out loud, but I'll have a hard } \\
\text { time concentrating on pronouncing the words correctly and understanding } \\
\text { what's going on at the same time. }\end{array}$ \\
\hline 16 & Lydia & $\begin{array}{l}\text { Like when I'm reading something, I know what I'm reading but I'm having a hard } \\
\text { time paying attention to it. }\end{array}$ \\
\hline 17 & Jack & Yeah, so your mind is somewhere else. \\
\hline 18 & Lydia & If I have to read out loud, I don't know what I'm reading. \\
\hline 19 & Jack & $\begin{array}{l}\text { Uhhuh. } \\
\text { Well I think it is tough, you know, 'cause sometimes if you read something aloud } \\
\text { and you are trying to say it right and everything else, it's harder than if you are } \\
\text { reading quietly ... because sometimes-We were talking the other day about, } \\
\text { you know, Albert was mentioning, I think, sometimes when you are reading } \\
\text { along you're following things and all of a sudden you find out you're lost and } \\
\text { you have to go back and read again some. (.5) }\end{array}$ \\
\hline 20 & & $\begin{array}{l}\text { Uhmm ... how many of you like to study with other people in groups? } \\
\text { (Students raise hands) }\end{array}$ \\
\hline
\end{tabular}


construct another definition of academic homework reading: rather than an activity to get done, it is an activity that should create understanding.

When he spoke next, Jack confirmed that Lydia's experience is just like his: "Yeah, so your mind is somewhere else" (Turn 17). While she announced, "If I have to read out loud, I don't know what I am reading" (Turn 18), he agreed with, "Uhhuh" (Turn 19). He followed by speaking in the second person to generalize the application of their point to all the students in the room: "Cause sometimes if you read something aloud and you are trying to say it right and everything else, it's harder than if you are reading quietly" (Turn 19). The message from these brief moments of talk has significant implications for issues relevant to inclusion. The message conveyed is that the two have the same experience as all the students in the room regardless of their institutional designation-"gifted and talented," "learning disabled," "general," or "ESL." In this interaction, Jack bridged the gap between the linguistically and academically able and less able students' experience of reading difficult texts, and between a teacher's reading and students' readings. In this moment there is agreement, in that all members have similar difficulties with the same kind of reading activity. The implication of such alignment is profoundly meaningful in the messages it sends to Lisa and her classmates about what they can and should do, and about what counts as communicating and as being a communicator.

\section{Conclusion}

These kinds of interactions are the "creature" that is lost when attention is focused on getting students ready for the big test. Productively engaging academic and personal interchanges like the one between Jack, Lisa, Lydia, Jon, and Jody decrease. However, it is important to keep in mind that Marita had conversations like Jack's in her classroom too. That is why Nathan pushed to talk about his personal life as it was represented in his topic sentence. He had learned to see writing as not only an expression of a self he wanted to share, but as a medium for creating a self that could be socially acknowledged. Nevertheless, in each instructional interaction, Marita had to make a choice between what to focus and spend time on in doing what was best for Nathan. Her choice in the interchange presented earlier in this paper was to cut these types of conversations short and replace them with talk of another kind. The test loomed large and time was limited. Nathan had to learn so much to be ready. Marita's concern for Nathan to succeed on the test led her to instruct him to write as she believed test scorers expected. They had no time to discuss how his community supported its young people as athletes and maintained a drugless environment.

When what counts as expression, as being a writer, and as being a member of the class are collapsed to fit the high stakes frame, the classroom conversations that make the Nathans in our schools "real" writers disappear. This is a critical dilemma because when they do, our students most at risk of failure will most probably disappear as well. They become the spectral students on the fringes of our classrooms; or worse, as reports from Texas and other high stakes test states attest, they leave our schools. The dilemma cannot be easily resolved. Teachers cannot ignore the demands testing makes upon them. Since data were collected in Jack's classroom, he has had to address how standardized test accountability might compromise his goals for his students. He has yet to comfortably resolve his dilemma or receive substantial institutional assistance. 
Jack's and Marita's examples raise the question of how instructors can be assisted in resolving this conflict. The challenge is to assist teachers in integrating testing and their regular curriculum so that students who are least likely to participate and achieve will remain involved. Their examples also suggest one possible move toward a solution. Rendering their own classroom talk visible to teachers-by asking them to review videotapes or read transcripts of their own teaching-is a powerful tool for teacher change. For Marita, seeing on videotape what she had said to Nathan in the episode described here, and reflecting in an interview how she could have spoken differently to him to accomplish all of her objectives, was a useful exercise. She determined that she would respond more inclusively to Nathan the next time. Her actions, and those of other teachers with whom I work and who have learned from observing the way they talk to students, suggest that teachers would gain from raising their consciousness about their instructional discourse.

The practical questions become, "How can teachers be assisted in observing the ways that they talk with students?" and, "How can teachers productively analyze their instructional talk?" One promising answer emerges from the research methodology described in this article, which I have been experimenting with in teacher education and professional development programs since 1993 (see also Rex, Murnen, Hobbs, \& McEachen, 2002). Teachers' analysis of their classroom discourse, while complicated, is doable. To accomplish it, they must coordinate institutional logistics, video technology, and personal motivation as well as, most importantly, knowledge of how to productively "see" what they do interactively with their students. Their analytical tool box should include but not be limited to concepts such as positioning, footing, face saving, power and solidarity, and the analytical categories of turn taking, topic, and appropriation (Johnstone, 2002).

With such training, teachers come to retrospectively analyze moments of their teaching to address their own questions and concerns. They replay relevant interactions that flew by unnoticed while they consciously attended to other demands. During those analyses, they observe what a student had said to trigger their response, what they had replied, what that reply made possible, and what it constrained. They compare their discursive moves and the movement of instruction with their objectives for the lesson and their goals for their students. They consider what they could have said instead, and what they might say the next time a similar case arises to more closely approximate their objectives and goals.

Helping teachers conduct discourse analyses of their own classroom practices could assist them in identifying moments of conflict between their internally avowed curriculum and externally imposed test prep objectives. When teachers avow the importance of inclusive classroom talk, self-discourse analysis can provide the reality check needed to prevent inadvertent "loss of the creature."

In addition, professional development opportunities for experienced teachers can help them build discourse analysis knowledge. By studying with colleagues a variety of robust segments of taped and transcribed classroom instruction, they can learn applications for analyzing their own discourse and build collaborations that could lead to taping and analyzing each others' practice. After all, understanding the use of language means understanding the process of discourse through which people constantly figure out what to say and how to say things, in the process of interacting with others (Johnstone, 2002). 


\section{References}

Ainscow, M. (1993). Teacher education as a strategy for developing inclusive schools. In R. Slee (Ed.), Is there a desk with my name on it? (pp. 201-218). Washington, DC: Falmer Press.

Alton-Lee, A., \& Nuthall, G. (1992). Children's learning in classrooms: Challenges to developing a methodology to explain “opportunity to learn.” Journal of Classroom Interaction, 27(2), 1-7.

Bloome, D., Puro, P., \& Theodorou, E. (1989). Procedural display and classroom lessons. Curriculum Inquiry, 19(3), 265-291.

Borko, H., \& Eisenhart, M. (1989). Reading ability groups as literacy communities. In D. Bloome (Ed.), Classrooms and literacy (pp. 107-134). Norwood, NJ: Ablex Publishing Corporation.

Bos, C., \& Fletcher, T. (1997). Sociocultural considerations in learning disabilities inclusion research: Knowledge gaps and future directions. Learning Disabilities Research and Practice, 12(2), 92-99.

Bourdieu, P. (1977). Outline of a theory of practice. Cambridge: Cambridge University Press.

Bourdieu, P. (1990). The logic of practice. Stanford: Stanford University Press.

California Department of Education. (n.d.). English-Language Arts: Content Standards for California Public Schools. Retrieved January 8, 2002, from http://www.cde.ca.gov/standards/reading/

Cazden, C. (2001). Classroom discourse ( $2^{\text {nd }}$ edition). Portsmouth, NH: Heinemann.

Cochran-Smith, M. (1984). The making of a reader. Norwood, NJ: Ablex Publishing Corporation.

Collins, J. (1986). Differential treatment in reading instruction. In J. Cook-Gumperz (Ed.), The social construction of literacy. New York: Cambridge University Press.

Corbett, H. D., \& Wilson, B. L. (1991). Testing, reform, and rebellion. Norwood, NJ: Ablex Publishing Corporation.

Darling-Hammond, L. (1988). Accountability and teacher professionalism. American Educator, 12, 8-13.

Donmoyer, R. (1990). Generalizability and the single-case study. In E. W. Eisner \& A. Peshkin (Eds.), Qualitative inquiry in education: The continuing debate (pp. 175-200). New York: Teachers College Press.

Edwards, D., \& Mercer, N. (1987). Common knowledge: The development of understanding in the classroom. New York: The Falmer Press.

Fairclough, N. (1993) Critical discourse analysis and the marketization of public discourse: The universities. Discourse and Society, 4, 133-168.

Forman, E. A., \& McCormick, D. E. (1995). Discourse analysis, a sociocultural perspective. Remedial and Special Education, 16(3), 150-158.

Gee, J. (1996). Social linguistics and literacies: Ideology in discourses. London: Taylor and Francis.

Gee, J., \& Green, J. (1998). Discourse analysis, learning, and social practice: A methodological study. Review of Research in Education, 23, 119-170.

Geertz, C. (1973). The interpretation of cultures. New York: Basic Books.

Gilmore, P. (1987). Sulking, stepping and tracking: The effects of attitude assessment on access to literacy. In D. Bloome (Ed.), Literacy and schooling (pp. 98-120). Norwood, NJ: Ablex Publishing Corporation.

Goodenough, W. H. (1981) Culture, language, and society. Menlo Park, California: Cummings.

Grant, S. G. (2001). An uncertain lever: The influence of state-level testing in NewYork on teaching social studies. Teachers College Record, 103(3), 398-426.

Graue, M. E. (1993). Integrating theory and practice through instructional assessment. Educational Assessment, 1, 293-309.

Green, J. L. \& Dixon, D. (1993). Introduction to talking knowledge into being: Discursive and social practices in classrooms. Linguistics and Education, 5(3\&4), 231-240.

Gumperz, J. (1986). Interactional linguistics in the study of schooling. In J. Cook-Gumperz (Ed.), The social construction of literacy. New York: Cambridge University Press.

Heath, S. B. (1983). Ways with words: Language, life, and work in communities and classrooms. New York: Cambridge University Press.

Johnstone, B. (2002). Discourse analysis. Malden, MA: Blackwell.

Keogh, B., Gallimore, R., \& Weisner, T. (1997). A sociocultural perspective on learning and learning disabilities. Learning Disabilities Research and Practice, 12(2), 107-113.

Lieberman, A. (1992). School/university collaboration: A view from the inside. Phi Delta Kappan, 74, 147-152, 154, 156.

Linn, R. (2000). Assessments and accountability. Educational Researcher, 29(2), 4-16.

McNeil, L. M. (1988). Contradictions of control: School structure and school knowledge. New York: Routledge.

McNeil, L. M. (2000). Creating new inequities: Contradictions of reform. Phi Delta Kappan, 81(10), 728-734.

Meyers, J. (1993). The social contexts of school and personal literacy. Reading Research Quarterly, 27(4), 296-333.

Mitchell, J. C. (1984). Typicality and the case study. In R. F. Ellen (Ed.), Ethnographic research: A guide to general conduct (pp. 238-241). New York: Academic Press.

Moll, L., Diaz, S., Estrada, E., \& Lopes, L. (1992). Making contexts: The social construction of lessons in two languages. In M. Saravia-Shore \& S. Arvizu (Eds.), Cross-cultural literacy, ethnographies of communication in multiethnic classrooms (pp. 339-366). New York: Garland Publishing.

Olson, L. (2000). Worries of a standards "backlash" grow [Electronic version]. Education Week, 19(30), 1, 12-13.

Palincsar, A. (1997). Introduction. Review of educational research, 67(4), 373-375.

Percy, W. (1997). The message in the bottle. New York: The Noonday Press, Farrar, Straus, \& Giroux.

Pipho, C. (2000). The sting of high stakes testing and accountability. Phi Delta Kappan, 81(9), 645-646. 
Rex, L. A. (1994). A social view of composing from insiders' perspectives: The roles and relationships of teacher and students. In C. Kinzer \& D. Leu (Eds.), Multidimensional aspects of literacy research, theory, and practice: Forty-third yearbook of the national reading conference (pp. 560 -571). Chicago, IL: National Reading Conference, Inc.

Rex, L. A. (1997). Making a case: A study of the classroom construction of academic literacy. Unpublished doctoral dissertation, University of California, Santa Barbara.

Rex, L. A. (2000). Judy constructs a genuine question: A case for interactional inclusion. Teaching and Teacher Education, 16, 315-333.

Rex, L. A. (2001a). The remaking of a high school reader. Reading Research Quarterly, 36(4), 288-314.

Rex, L. A. (2001b, November). Teachers'(ings') tug of war: Exploring complex relationships between high stakes test accountability pressures, teaching, and student performance. Paper presented for the research strand at the National Council of Teachers of English Conference, Baltimore, MD.

Rex, L. A. (2002). Exploring orientation in remaking high school readers' literacies and identities. Linguistics and Education, 13(3), 271-302.

Rex, L. \& McEachen, D. (1999). "If anything is odd, inappropriate, confusing, or boring, it's probably important": The emergence of inclusive academic literacy through English classroom discussion practices. Research in the Teaching of English, 34(1), 65-129.

Rex, L. A., Murnen, T. J., Hobbs, J., \& McEachen, D. (2002). Teachers' pedagogical stories and the shaping of classroom participation: "The Dancer" and "Graveyard Shift at the 7-11." American Educational Research Journal, 39, 765-796.

Rex, L \& Nelson, M. (2001, April). What "teaching to the test" means when we look closely at classroom teaching and learning. Paper presented for The American Educational Research Association, Seattle, WA.

Rex, L. A. \& Nelson, M. (in press). How teachers' professional identities position high stakes test preparation in their classrooms. Teachers College Record.

Santa Barbara Classroom Discourse Group. (1992). Constructing literacy in classrooms: Literate action as social accomplishment. In H. H. Marshall (Ed.), Redefining student learning (pp. 119-150). Norwood, NJ: Ablex Publishing Corporation.

Shepard, L. (2000, April). The role of assessment in a learning culture. Presidential Address presented at the annual meeting of the American Educational Research Association, New Orleans, LA.

Skrtic, T. (1991). The special education paradox: Equity as the way to excellence. Harvard Educational Review, 61(2), $148-206$.

Skrtic, T., Sailor, W., \& Gee, K. (1996). Voice, collaboration, and inclusion: Democratic themes in educational and social reform initiatives. Remedial and Special Education, 17(3), 142-157.

Slee, R. (1993). Inclusive learning initiatives: Educational policy lessons from the field. In R. Slee (Ed.), Is there a desk with my name on it? The politics of integration (pp. 185-200). Washington, DC: The Falmer Press.

Tuyay, S., Jennings, L., \& Dixon, C. (1995). Classroom discourse and opportunities to learn: An ethnographic study of knowledge construction in a bilingual third grade classroom. Discourse Processes, 19(1), 75-110.

Wessman, C. (Winter 2000). ADE Bulletin, 124, 29-32.

Received February 8, 2002

Accepted October 10, 2002 